\section{CONTRIBUCIÓN AL ANÁLISIS SOCIOLÓGICO DE LA CREATIVIDAD Y LA DIGITALIZACIÓN DEL CAMPO CULTURAL: CREACIÓN, INTERMEDIACIÓN Y CRISIS}

\author{
Joaquim Rius-Ulldemolins \\ Universitat de València \\ ORCID iD: https://orcid.org/0000-0003-0582-2786 \\ joaquim.rius@uv.es \\ Juan Pecourt \\ Universitat de València \\ ORCID iD: https://orcid.org/0000-0001-6218-6398 \\ juan.pecourt@uv.es \\ Juan Arturo Rubio Arostegui \\ Universidad Antonio de Nebrija \\ ORCID iD: https://orcid.org/0000-0002-7236-2866 \\ jrubioa@nebrija.es
}

Cómo citar este artículo/Citation: Rius-Ulldemolins, J., Pecourt, J. y Rubio Arostegui, J. A. (2019). Contribución al análisis sociológico de la creatividad y la digitalización del campo cultural: creación, intermediación y crisis. Arbor, 195 (791): a491. https://doi.org/10.3989/arbor.2019.791n1004

Recibido: 19 abril 2015. Aceptado: 8 marzo 2016.

RESUMEN: La llamada transición al paradigma digital está erosionando la autonomía del campo cultural que se había conseguido durante los siglos XIX y XX, subyugándolo a las dinámicas económicas y tecnológicas. Sin embargo, el discurso hegemónico tiende a interpretar esta como un proceso netamente positivo para la creatividad, centrando la atención en el aumento de la disponibilidad de recursos informativos y de herramientas para la creación. No obstante, un análisis desde las teorías y los conceptos de la sociología de la cultura nos revela un balance más ambivalente. Si bien la noción de autoría y creación puede ser interpretada desde un punto de vista más cooperativo y relativista, es discutible que pueda ser eliminada. Además, si bien el análisis de la intermediación cultural debe tener en cuenta el papel más complejo y activo de los intermediarios, difícilmente se puede concebir el sistema cultural sin su existencia. En definitiva, el artículo se propone contrastar los discursos sobre la transición a lo digital con las teorías clásicas y contemporáneas de la sociología de la cultura para, de este modo, plantear futuras líneas de investigación sociológica sobre las consecuencias en los agentes y en la industria cultural en su conjunto. Con ello se pretende generar una perspectiva neutral que tenga en consideración los efectos sociales y sistémicos de la tecnología en la creatividad de los sectores culturales.

PALABRAS CLAVE: Paradigma digital; industrias culturales; creatividad; intermediarios culturales; sociología de la cultura.

\section{CONTRIBUTION TO SOCIOLOGICAL ANALYSIS OF CREATIVITY AND THE DIGITIZATION OF CULTURAL FIELD: CREATION, INTERMEDIATION AND CRISES}

Copyright: (C) 2019 CSIC. Este es un artículo de acceso abierto distribuido bajo los términos de la licencia de uso y distribución Creative Commons Reconocimiento 4.0 Internacional (CC BY 4.0).
ABSTRACT: The so-called transition to the digital paradigm is eroding the autonomy of the cultural field achieved during the XIX and XX Centuries, subjugating them to economic and technological dynamics. However, the hegemonic discourse tends to interpret this as an overall positive process for the creative domain, focusing on the increase in information resource and creativity tool availability. However, an analysis of the theories and concepts of the sociology of culture reveals a more ambivalent balance. While the notion of authorship and creation can be interpreted from a more cooperative and relativistic view it is arguable whether this concept can be eliminated altogether. Also, although cultural intermediaries should be analyzed from a more complex and active role, one can hardly conceive the cultural system without them. In short, the article aims to contrast discourses about the transition to digital with classical and contemporary theories of the sociology of culture, in order to draw future lines for sociological research on the impact on agents and the cultural industry as a whole. The aim of this analysis is to generate a neutral perspective that takes into account the social and systemic effects of technology on the creativity of cultural sectors. 


\section{INTRODUCCIÓN: CRISIS SISTÉMICA DE LA CULTURA Y TRANSICIÓN AL PARADIGMA DIGITAL}

El sector cultural se enfrenta en este inicio de siglo XXI con una situación paradójica. Por un lado, se confirma la centralidad social y económica de los elementos culturales y simbólicos, fenómeno que algunos autores diagnosticaron en los pasados años setenta y que calificaron como el advenimiento de la sociedad postindustrial (Bell, 1991). Pero, por otro lado, la esfera cultural autónoma tal como la analizó Bourdieu (2002), con su polo de arte vanguardista, se ha sumido en una crisis sistémica en sus mecanismos de producción, distribución y valoración. Un fenómeno que es observable en el ámbito internacional y muy especialmente en España, donde el sector cultural ha experimentado una crisis especialmente aguda con relación a otros países avanzados (Rubio Arostegui, Rius Ulldemolins y Martínez Illa, 2014). En este contexto la irrupción de las nuevas tecnologías digitales de la información y la comunicación ha tenido un gran impacto. Veinte años después de la popularización de internet y de su multiplicación de usos en la esfera económica y social la red ha tenido unos efectos decisivos a medio plazo y, a la vez, ambivalentes para la esfera cultural (Rius Ulldemolins, 2015). Por un lado, internet ha facilitado la participación social en ámbitos técnicos y simbólicos especializados a partir de lo que Granovetter (1973) caracterizó como lazos sociales débiles, es decir a partir de una organización descentralizada y horizontal (Shirky, 2008). Ello permite fundar comunidades sociales de producción o consumo cultural -las audiencias activas, como las analiza Jenkins (2008)- al margen de los intermediarios tradicionales del sector cultural como las editoriales, las discográficas o las galerías de arte. Esta nueva organización social de la creación posibilita según determinados puntos de vista el surgimiento de una nueva creatividad abierta y no coartada por los derechos de autor (Lessig, Córdoba y Candeira, 2005) y potenciaría las posibilidades de acceso a la cultura, creada y accesible a todos a partir del paradigma open (Ariño Villarroya, 2009).

Sin embargo, por otro lado, desde hace unos años va creciendo una corriente más escéptica respecto a las transformaciones que impone el paradigma digital en el mundo cultural, señalando su falta de sostenibilidad, al destruir sus bases materiales y las cadenas de cooperación existentes y al no crear otras nuevas que consigan sustentar todo el sistema cultural (Levine, 2013). Estas visiones, como la desarrollada por Eugeny Morozov, acusan a los partidarios de las transforma- ciones de internet de partir de un axioma ciberutópico (Morozov, 2012; Morozov, 2013), que considera todos los cambios producidos por las nuevas tecnologías digitales como positivos y no tiene en cuenta los efectos negativos. Los críticos a esta visión ciberutópica señalan que interpreta la realidad solo desde el punto de vista de internet, desde el llamado internet-centrismo, y tiene una fe ilimitada en su capacidad para resolver problemas, ignorando sus efectos no deseados. Así, uno de los puntos débiles de la perspectiva ciberutópica es que, como analiza César Rendueles (2013), se sobreestima la capacidad de transformación a partir de los vínculos débiles, se sobredimensiona la capacidad de organización de la producción y de regular el acceso a los bienes comunes culturales. El problema de esta visión es que hace experimentar una excesiva confianza en la capacidad transformadora de las tecnologías y descuida los procesos de fragilización de las relaciones sociales experimentados a raíz de la irrupción de esta nueva fase del capitalismo iniciada en los años setenta (Donzelot et al., 2007; Putnam, 2000) y del creciente dominio de las multinacionales y de los tecnólogos sobre la producción y la intermediación de los bienes y servicios de todo tipo y especialmente de los culturales (Lanier, 2010). Asimismo, esta visión ciberutópica ha sido crecientemente aplicada a la esfera de la cultura, centrando el futuro y la solución a los retos del sector cultural en internet sin atender a los efectos negativos que en sectores como la música o el cine está teniendo a corto y medio plazo (Levine, 2013).

En definitiva, a nuestro entender, el debate sobre el impacto de internet en la cultura se encuentra en una forma muy ideológica y polarizada y no se está respondiendo de forma ponderada y neutral a la pregunta sobre qué efectos tiene lo que venimos a definir como la digitalización del campo cultural. Utilizamos este concepto y no otros términos que consideramos confusos, como cultura digital o más recientemente bienes comunes culturales. En este artículo partimos de la idea de que, a diferencia de ciertos discursos que construyen la noción de cultura digital y que insisten en que las diferencias respecto a la cultura anterior se deben a la aparición de las llamadas nuevas tecnologías, no podemos hablar en propiedad de una cultura en términos restringidos (en la acepción humanística y sociológica, como la que señala Antonio Ariño (1997)), diferenciada de la que ha existido desde finales del siglo XVIII e inicios del siglo XIX. No utilizaremos por lo tanto la expresión cultura digital, sino que consideraremos la digitalización como un proceso inscrito en el campo cultural. ${ }^{1}$ Asimismo, por ello tam- 
bién entendemos que, si bien hace falta actualizar las herramientas de análisis utilizados para el análisis cultural, la aportación de la sociología de la cultura aún está en gran medida vigente.

Por ello, en este artículo pretendemos recuperar las aportaciones principales de la sociología de la cultura, especialmente de la francesa y de la norteamericana desde los años setenta. La primera, desarrollada bajo la influencia de la corriente del estructuralismo genético de Pierre Bourdieu y su escuela (Bourdieu, 1977; Bourdieu, 2002) y más tarde desde una perspectiva interaccionista y que fructificó en profundos estudios sociológicos de los mercados, las profesiones artísticas y la creatividad como trabajo (Menger, 2009; Moulin, 1983; Moulin, 1992; Moulin y Cardinal, 2012; Quemin 2013). Asimismo, está surgiendo una nueva corriente de la sociología de la cultura centrada en la intermediación cultural ${ }^{2}$. Esta corriente parte de un consenso en concebir la creación como un acto colectivo más que individual, que es fruto de múltiples protagonistas y no solo el resultado de la inspiración o del trabajo de un artista individual y aislado. Por ello esta corriente ha centrado su atención en el rol de los intermediarios culturales como organizadores del sector cultural y creadores de la reputación artística (Lapierre y Roueff, 2013). Por otro lado, la sociología de la cultura introduce un giro institucionalista que inspira una larga tradición de trabajos (DiMaggio, 2000). Desde este enfoque la creatividad cultural se relaciona con los marcos organizativos, profesionales y de mercado, pudiéndose analizar la influencia de los sistemas culturales sobre una mayor o menor diversidad y riqueza en la creación de los diversos sectores culturales (Peterson y Anand, 2004).

El objetivo del artículo es establecer la contribución de la sociología ${ }^{3}$, centrándonos en estas dos corrientes mencionadas, al análisis de la relación entre la creatividad y la digitalización del campo cultural. Por ello contrastaremos los conceptos sociológicos con las posiciones actualmente hegemónicas en muchos sectores que consideran las nuevas tecnologías y sus consecuencias como un vector positivo para la creatividad. Así, el artículo pretende ser crítico con esta perspectiva e iniciar una línea de investigación más neutra y ponderada. Para ello nos centraremos en al análisis de la dimensión colectiva de la creación cultural, considerando las teorías que establecen la existencia de estructuras y rituales de interacción. En segundo lugar, estudiaremos el rol y la aportación de los intermediarios en los procesos creativos y en la creación del valor cultural en relación con los públicos, así como las diferentes dimensiones organizativas y profesionales. En tercer lugar, introduciremos algunas proposiciones básicas del discurso ciberutópico (Morozov, 2012) que recompone el papel de los productores (y minusvalora el de los intermediarios) dentro del ámbito cultural. Ello nos permitirá finalmente contrastar la concepción humanística clásica de la cultura con la nueva concepción ciberutópica y establecer las aportaciones más relevantes de la sociología de la cultura al examen de la transición al paradigma digital y la creatividad. Por último, estableceremos a modo de cierre los retos que a nuestro entender deben abordarse para comprender la digitalización del campo cultural y qué aportaciones puede hacer la sociología en relación con la creatividad.

\section{ANÁLISIS SOCIOLÓGICO DE LOS AUTORES: ESTRUCTURAS E INTERACCIONES Y LA CREATIVIDAD}

El estudio sociológico de la creatividad y la producción de valor cultural se ha abordado desde diferentes corrientes: por una parte, la corriente durkheimiana, centrada en la configuración de ritos institucionalizados que contribuyen a focalizar el interés simbólico (Collins, 2009) y, por otra parte, la corriente weberiana que analiza la configuración social del genio. En este trabajo tomaremos ideas de ambas corrientes, con especial atención a las aportaciones de Bourdieu y Collins, que siguen la estela de Durkheim, y de Menger, más cercano a las posiciones weberianas.

\section{Los creadores, las estructuras del campo artístico: la aportación de Pierre Bourdieu}

Bourdieu identifica una tensión fundamental entre el campo de producción masiva y el campo de producción especializada (Bourdieu, 2002). El primero produce, difunde y legitima productos simbólicos que responden a intereses procedentes del mundo político y económico, de lo que Bourdieu llama el "campo de poder", y que por tanto son ajenos a la lógica específica del mundo cultural (la lógica del "interés por el desinterés"). En el segundo se encuentra la producción cultural guiada por criterios estrictamente culturales, es decir por esquemas mentales y códigos de comportamiento que establecen una clara demarcación frente a otros espacios sociales como la empresa o la administración. El campo cultural especializado es el mundo del "arte por el arte", de las acciones que se mantienen alejadas de las necesidades prácticas de la sociedad (o, en otras palabras, de los intereses específicos), de las iniciativas y propuestas enmarcadas dentro de los principios estructurantes de los campos 
especializados. La existencia de dos lógicas culturales implica, por tanto, una confrontación directa entre dos formas de entender la producción cultural, la centrada en factores culturales (en intereses puramente culturales) y la que se somete a factores extra-culturales (dictados por el estado o el mercado).

En trabajos como Las reglas del arte, Bourdieu (2002) describe el proceso socio-histórico que conduce a la formación de campos culturales autónomos en la Francia de finales del siglo XIX (el campo artístico, el campo literario, etc.). No se trata de un proceso mecánico y espontáneo o del resultado inevitable de determinadas transformaciones económicas, científicas o tecnológicas. Es la consecuencia de un entramado de luchas sociales, de diversas iniciativas individuales y colectivas, que subvirtieron la floreciente cultura comercial burguesa del siglo XIX y promovieron espacios sociales de carácter autónomo guiados por la experimentación y la renovación, por la ruptura constante de los límites estéticos y cognitivos en contraposición a un arte burgués. Un arte perfectamente amoldado a los gustos prefabricados del público mayoritario (significativamente uno de los apartados de Las reglas del arte se titula "la conquista de la autonomía"). Sin embargo, lo que se observa a finales del siglo $X X$ y principios del siglo $X X I$, según el autor francés, es el proceso contrario: los campos culturales autónomos construidos durante el siglo pasado están sufriendo un proceso de indiferenciación y, por tanto, de pérdida de autonomía. Los principios específicos de los campos culturales especializados están en crisis, son cuestionados por nuevos agentes sociales que tienen un poder de decisión cada vez más importante en las esferas artísticas. El resultado de este proceso es el desmantelamiento progresivo de los espacios especializados. Los medios tecnológicos, que Bourdieu considera una forma de capital cultural objetivado (Bourdieu, 1997), no influyen de manera neutra y aséptica en la reconfiguración de los campos culturales, como parecen afirmar muchos de los teóricos de la cultura digital, sino que formarían parte de las estrategias políticas impuestas por determinados agentes culturales para orientar el sentido del cambio cultural en una dirección concordante con sus intereses específicos.

Como vemos, Bourdieu realiza una lectura bastante negativa de este proceso y, en consecuencia, reivindica una recuperación de las luchas sociales para mantener la autonomía conquistada en el siglo anterior. Solo desde la autonomía podrán mantenerse los logros fundamentales alcanzados por los distintos ám- bitos de la creación; esta constituye el prerrequisito básico de la creatividad y la innovación cultural (Bourdieu, 2002). Esto es así porque la creatividad está ligada a factores estructurales, a una determinada constitución de los campos culturales, tanto en el ámbito interno (donde se entabla una competencia que persigue acumular determinados capitales que se consideran legítimos) como en el externo (donde se asegura un cordón sanitario frente a la influencia de los grandes poderes sociales) (Pecourt, 2007). El autor francés considera que solamente los campos culturales especializados aportan las condiciones necesarias para impulsar la innovación cultural. Los campos culturales aportan los recursos (capitales) y las predisposiciones (habitus) específicas que fomentan la renovación interna, la aparición de nuevas cohortes de creadores, la sustitución de las propuestas y de los estilos artísticos. Esta innovación se basa en la competencia entre agentes reconocidos dentro del campo, que aspiran a cambiar la normativa autóctona, el sistema jerárquico establecido, y por tanto los criterios de valoración y consagración cultural, pero manteniendo siempre la creencia en los fundamentos del campo, es decir, conservando los principios básicos que lo constituyen desde su fundación. Según Bourdieu, las innovaciones que se producen en los campos culturales especializados suelen funcionar como revoluciones internas que promueven la vuelta a los orígenes, ante un estado de cosas que se considera desfasado o desviado de los principios fundacionales (Bourdieu, 2002). Solo aquellos individuos socializados dentro de la lógica del campo sabrán detectar los verdaderos frentes de innovación, frente a los amateurs y los naifs, que, a pesar de su buena voluntad, tenderán a errar el tiro y a experimentar en los lugares equivocados, alejándose de cualquier posibilidad de innovación.

Bourdieu considera que en los campos culturales existen jerarquías fundamentales que condicionan sus mismas posibilidades de existencia. En primer lugar, podemos distinguir entre los creadores (escritores, artistas, filósofos, académicos) y los intermediarios culturales (traductores, críticos, galeristas, representantes, editores, conservadores, etc.), situados de manera diferenciada en la cadena de producción cultural. Aunque las sociologías postmodernas tienden a diluir las diferencias entre los productores especializados y los intermediarios culturales -a los que Featherstone (2000) denomina las "nuevas clases medias"-, Bourdieu (2002) tiende a mantener las diferencias estructurales entre ambos estratos. Los intermediarios culturales están situados tanto en los campos especializados como en los masificados y condicionan 
en gran medida los procesos de selección y evaluación cultural. Bourdieu se muestra muy crítico con el papel de los intermediarios culturales procedentes de los campos culturales masificados, aquellos directamente asociados a los medios de comunicación de masas y a las industrias culturales, porque considera que siguen criterios economicistas y administrativos, y por tanto dinamitan la autonomía básica que debería caracterizar a los campos de producción cultural especializada. En este contexto pueden situarse sus observaciones críticas sobre los intelectuales-periodistas y periodistas-intelectuales (Bourdieu, 1997). En segundo lugar, también podemos distinguir entre los productores especializados y los intelectuales "proletaroides", es decir, aquellos productores culturales que aspiran a ser reconocidos por los agentes legítimos de los campos especializados, pero sin contar con los recursos necesarios ni las predisposiciones adecuadas para formar parte de dichos submundos. Al no cumplir los requisitos para ser reconocidos en los campos especializados, los intelectuales "proletaroides" adoptan una posición revolucionaria que consiste en el derribo de las barreras tradicionales (por ejemplo, las distinciones entre cultura experta y cultura comercial) y en el cuestionamiento de la propia idea de la especialización. Las actuaciones revolucionarias suponen una estrategia alternativa para lograr el reconocimiento que no puede lograrse por las vías tradicionales. Desde la perspectiva de Bourdieu (1997) se trata de una aproximación subrepticia que no hace sino dinamitar las condiciones necesarias para la producción cultural especializada.

\section{La creación como ritual social y la competencia entre pequeños números: la aportación de Randall Collins}

Collins sitúa a las comunidades intelectuales al margen de los intereses del estado y del mercado y por tanto reacciona contra aquellas perspectivas (sobre todo el postmodernismo) que tratan de diluir las distinciones entre el mundo cultural, el político y el económico (Collins, 2005; Collins, 2009). Las comunidades intelectuales son espacios de conversación que tienen una estructura precisa y que funcionan de acuerdo a una normativa independiente. A diferencia de lo que afirmarían corrientes como el marxismo o el estructuralismo, Collins asegura que no es posible establecer conexiones directas entre los acontecimientos internos del mundo cultural y las decisiones tomadas en el mundo de la política y de la economía (o también de los avances procedentes de la esfera tecnológica). De hecho, la estructura básica que cohesiona a las comunidades intelectuales no es la in- fraestructura económica, la normativa jurídica ni las plataformas tecnológicas sino las interacciones cotidianas que se producen entre sus miembros, sus intercambios ritualizados en el seno de un colectivo que se mantiene relativamente alejado de los vaivenes de la sociedad mayoritaria (Collins, 2009).

Desde una perspectiva micro-sociológica, Collins pretende establecer las leyes de las conversaciones y los intercambios simbólicos que se dan en los diferentes campos culturales. Considera que estas actividades constituyen rituales de interacción específicos, sustentados en los encuentros presenciales y en la creación de lazos fuertes (Collins, 2009). Los miembros de las comunidades intelectuales por tanto coinciden en espacios físicos, en reuniones, en seminarios y congresos, e intercambian ideas que impulsan colectivamente la creatividad y la innovación. Estos rituales físicos no pueden sustituirse por rituales mediatizados porque el compromiso personal de los autores decae cuando las interacciones no se realizan cara a cara. Mediante la mediatización de las relaciones sociales es más difícil establecer un foco de atención común, es decir conseguir que todos los miembros del grupo compartan problemáticas comunes, y también es más difícil mantener el interés y la energía colectiva necesaria para que la conversación siga su curso. La importancia de la presencia física y de los lazos fuertes, reivindicada por Collins (1987), parece caracterizar a las comunidades intelectuales clásicas en las que se centra el autor norteamericano (filosófica, artística, literaria) y a las nuevas comunidades surgidas del mundo digital. Así, por ejemplo, Gabriella Coleman (2013) incide en la importancia de los congresos de hackers para construir un sentido de comunidad basado en la presencia física y en el intercambio no mediatizado de puntos de vista. Los hackers viven desperdigados en el ciberespacio, forman comunidades difusas caracterizadas por su amplia autonomía, por sus interacciones efímeras e intermitentes y por sus lazos sociales débiles (Coleman, 2013). Por esta razón, eventos presenciales como los congresos de hackers, que se complementan con actividades sociales muy diversas, son fundamentales para mantener la cohesión y la identidad de la comunidad hacker. La tecnología no suprime ni elimina la presencia física.

La presencia física y la creación de lazos fuertes que mantienen cohesionada la comunidad intelectual es además la condición básica de una innovación cultural que, según Collins (2009), difícilmente podría darse en contextos totalmente mediatizados. Los rituales de interacción son efectivos en contextos presenciales 
porque los encuentros cara a cara generan un contagio emocional entre los participantes que impulsa la creatividad. De este modo, la posición en la comunidad intelectual y la capacidad que tiene el individuo para establecer lazos fuertes con otros miembros se convierten en un recurso fundamental que impulsará la productividad y la creatividad del individuo. En términos generales, la comunidad intelectual está estratificada en un centro y una periferia. El criterio de estratificación central es la posesión de capital cultural, en el sentido que Bourdieu (1991) aporta a este término, pero también la posesión de un recurso fundamental que Collins (2009) denomina energía emocional. Según el sociólogo norteamericano, los rituales de interacción cara a cara suscitan un estado colectivo de "efervescencia emocional" que transmite a los participantes emociones positivas como la confianza, el entusiasmo o el placer, ingredientes básicos que permiten la elaboración de proyectos originales, creativos y rupturistas. Por tanto, la acumulación de energía emocional se relaciona de manera directa con la creatividad individual. Aun así, dentro de las comunidades intelectuales, no todo el mundo puede acumular la energía emocional necesaria para realizar un trabajo ambicioso y sostenido en el tiempo; más bien al contrario, las emociones positivas se distribuyen de forma muy desigual: una minoría creativa que tiende a monopolizarla y una mayoría acomodaticia y poco productiva que no tiene acceso a ella. El núcleo de la comunidad intelectual mantendrá lazos fuertes y competirá por el reconocimiento colectivo mientras que la periferia se limitará a mantener relaciones débiles con el núcleo más productivo y sus producciones estarán destinadas al fracaso.

Frente a las teorías de la democratización cultural, Collins contrapone su ley de los pequeños números que sostiene la idea de la existencia de espacios de creación minoritarios. Según este autor, el núcleo de la comunidad intelectual es muy reducido y las posibilidades de atención que pueden recibir las diversas propuestas culturales muy escasas (Collins, 1989). El número de personas relevantes dentro de la comunidad intelectual oscila entre cuatro y seis, que son los individuos reconocidos por el conjunto de la comunidad (los ocupantes del centro del "espacio de atención intelectual") que compiten entre ellos y realizan las innovaciones más importantes. Esta estructura básica, fuertemente jerarquizada y sustentada en la concentración de capitales culturales y emocionales, provoca las dinámicas sociales específicas que conducen a la innovación. Un número menor de posiciones -el monopolio completo de los recursos culturales y emo- cionales por parte de un solo actor social- limitaría la innovación porque no se darían las condiciones básicas que producen el debate y el contraste de puntos de vista. Al mismo tiempo, un número excesivo de posiciones -la proliferación descontrolada de propuestas dentro del espacio de atención intelectual- también mermaría la creatividad de la comunidad intelectual, porque el crecimiento exponencial de posiciones limita la posibilidad de generar focos de atención común, dificulta que los creadores se enfrenten a problemáticas comunes y compitan entre ellos y produce una fragmentación del espacio de atención, una atomización de la comunidad intelectual que conduce a la esterilidad creativa (se reducen los debates, las polémicas, las relaciones fuertes) y al desmantelamiento de la comunidad. Según Collins, las condiciones actuales del trabajo creativo, caracterizadas por la saturación y la masificación de las comunidades culturales, están imponiendo un estado de agotamiento y de inhibición ante cualquier posibilidad de innovación cultural. A diferencia del análisis presentado por Bourdieu, Collins asegura que el origen de la crisis contemporánea de los campos culturales no se encuentra en la colonización creciente de los campos económicos (a través de la mediación de los medios de comunicación de masas, a los que podríamos añadir las redes sociales) sino en la propia constitución interna de estos espacios y en la fragmentación descontrolada de las posiciones sociales (Collins, 2009).

Podríamos decir, en definitiva, que el papel dado por los autores reseñados a las nuevas tecnologías tiene elementos comunes que cuestionan algunos principios básicos de los gurús de la cultura digital, pero también elementos claramente diferenciales. Ambos autores cuestionan dos ideas fundamentales de la vulgata digital: a) la neutralidad estructural de las nuevas tecnologías y su papel en el ámbito de la democratización cultural y b) la idea de que el desarrollo de las nuevas tecnologías favorezca la creatividad en el ámbito cultural. Sin embargo, también aportan enfoques diferenciados: Bourdieu considera que la centralidad de las nuevas tecnologías está asociada a las estrategias políticas de determinados sectores del campo cultural para posicionarse de una manera más favorable en el campo (en general, se tratará de intermediarios culturales que aspiran a romper las barreras entre los intermediarios y los productores) mientras que para Collins la mediatización y la digitalización de las interacciones entre los miembros de la comunidad digital puede tener consecuencias perversas y producir el efecto opuesto al deseado, es decir, la pérdida de creatividad e innovación, debido al des- 
censo de la energía emocional de los participantes y a la sustitución de los lazos fuertes por los lazos débiles en el ámbito de las interacciones individuales.

Actos de valoración y mecanismos de selección institucional: la aportación de Pierre-Michel Menger

Las contribuciones del sociólogo francés Pierre-Michel Menger las podemos situar en la corriente weberiana que analiza la configuración social del genio creador (Menger, 2009). Ciertamente otros autores han trabajado en el análisis social del genio, como el caso de Mozart (Elías, 2002), de Beethoven (DeNora, 1995) o de Van Gogh (Heinich, 1992), realzando los condicionantes sociales a los que se ha enfrentado su creatividad y la construcción de su carrera artística y la pugna de estos creadores -en algunos casos exitosa y en otros frustrada- para conseguir una autonomía en su creación y una legitimidad artística y no influida por otros factores (religiosos, políticos o comerciales) de la recepción de su obra. Por lo tanto, en estos estudios se insiste en la perspectiva del carisma como producto social, en el que la creación del valor cultural proviene del reconocimiento. Sin embargo, más allá de estos análisis de carácter socio-histórico, desde una perspectiva más meso-sociológica Menger (2009) introduce en el análisis de los procesos cotidianos de reconocimiento que se desarrollan a partir de dos mecanismos. Por una parte, por los continuos actos de valoración que el propio medio organiza, en el que diferencias pequeñas de talento son consideradas esenciales y generan grandes distancias de reputación. Este apoyo deriva en mejores opciones de aprendizaje (acceso a becas, instituciones de formación o proyectos artísticos, que son el mecanismo fundamental de aprendizaje, el aprender con la práctica). Asimismo, el mayor reconocimiento ofrece mayor seguridad y protección hacia el fracaso, lo que incentiva a su vez la capacidad innovadora, cerrando de este modo un círculo virtuoso. Por otra parte, por los mecanismos de selección formales institucionales y del mercado que abren la posibilidad del reconocimiento, del aprendizaje entre la elite y que fomentan la reputación masiva, generando un mecanismo parecido al winners take all, en el que una pequeña élite concentra todos los indicadores de reputación (Menger, 1999). Así, todos estos esquemas de análisis insisten en la importancia de las interacciones en la creación, el reconocimiento y la fijación del valor. Por ello debemos plantearnos si existen sistemas culturales que favorecen más que otros la generación de valor cultural y si pueden existir evoluciones o disfunciones del sistema cultural que puedan disminuir la capacidad de generar creatividad en el sistema cultural, una pregunta que adquiere toda su relevancia al plantear la transición al paradigma digital de los sectores culturales.

\section{LOS INTERMEDIARIOS CULTURALES Y LA CREACIÓN CULTURAL}

La creación como proceso colectivo y la creación de valor cultural y económico: el rol de los intermediarios

En primer lugar, debemos aclarar que la noción de intermediario es del todo inapropiada para el sector cultural, al no poderse separar claramente la fase de creación de la fase de producción o distribución, produciéndose valor o capital simbólico en todos los segmentos de la cadena de cooperación y de forma colectiva por parte de todo el campo cultural (Bourdieu, 2002). En el mismo proceso de creación intervienen diversas profesiones consideradas técnicas o de gestión pero que tienen un rol muy relevante a partir de una interacción micro en el mismo proceso y en la configuración del mismo producto final (Becker, 1984; Peterson, 1997).

Diversos sociólogos han relativizado la noción de autor en los campos culturales, señalando que se trata de una construcción ideológica basada en la ideología romántica del genio artístico (Williams, 1994; Williams, 2001). Algunos autores han señalado que la imagen por excelencia del artista, la de Van Gogh, y su trayectoria caracterizada por la vida turbulenta y el aislamiento social se asemeja a los relatos de la vida de los santos católicos y su martirologio. Y que en realidad los relatos sobre Van Gogh que lo presentan como un artista desconectado del mercado artístico subestiman el rol de diversos intermediarios en la construcción de su valor y de su éxito póstumo (Heinich, 1992). Asimismo, se puede señalar que el caso de este artista es, en realidad, más una excepción relacionada con los rasgos patológicos de su personalidad que una pauta de los artistas, como se puede observar en la vida de otros grandes artistas como Picasso (Franck, 2003). Picasso mantuvo muchas e intensas relaciones con sus marchantes, Vollard y Khanweiler, en una relación de intercambio y negociación sobre la forma de presentar y por lo tanto de dar valor a su obra, así como en el control de la venta de sus cuadros y de las condiciones económicas en las que lo hacían (Assouline, 1989).

Una de las aportaciones más interesantes en este campo la realiza Howard Becker, que adopta una mirada interaccionista en el mundo del arte (y por tanto relativista en cuanto a la noción de autoría) y esto lo 
lleva a revisar la figura del artista en función de su encaje en las cadenas de cooperación de trabajo artístico (Becker, 1984). Según su perspectiva el arte es una actividad colectiva en la que participan multitud de intermediarios, además de los considerados creadores. En cuanto los artistas no encuentran los intermediarios adecuados para su trabajo encuentran otras formas de desarrollarlo, pero esto a la vez también cambia el resultado final y abre nuevas posibilidades. Además, hay unas reglas de funcionamiento en los mundos del arte y una división del trabajo que es arbitraria y que, aunque resulta difícil de modificar, evoluciona constantemente. Por ejemplo, en el campo de la música ha habido una constante tensión en la noción de autoría con relación a los intérpretes: si bien desde la consolidación de la esfera cultural como esfera autónoma en el siglo XIX la tendencia ha sido considerar al compositor como autor y al músico-intérprete como intermediario, diversas tendencias musicales como el jazz o la música contemporánea ponen en duda esta convención. Y tampoco queda claro una división entre autor e intermediario en campos como el del arte conceptual o el de las grandes esculturas en el que el artista no realiza la obra, o en el caso de la industria cinematográfica, en el que las obras son producidas colectivamente y existen diversas autorías e intervenciones técnicas muy relevantes (guionista, director de fotografía, compositor de la banda sonora, etc.).

Asimismo, los intermediarios juegan un papel muy relevante en la creación del valor cultural y su reputación, al tratarse de productos, como las obras de arte visuales, sin un valor a priori definido por el material del que están hechos o las horas de trabajo dedicadas a su elaboración, y que deben ser valorizadas simbólicamente (Becker, 1994; Moulin, 1992). Por otra parte, en el caso de las obras orientadas al sector más vanguardista, estas carecen de un público y una demanda previamente constituida (Bourdieu, 2002). Asimismo, en las siguientes etapas de la carrera creativa no se puede deslindar a medio plazo el valor en sí del valor económico de las obras construido por el mercado (Becker, 1994). Argumentan los críticos de la intermediación cultural que su actuación se base en crear una escasez artificial y en contribuir a reproducir una escasez de demanda (Lessig, Córdoba y Candeira, 2005). Sin embargo, los estudios de profesiones culturales en los que se ha creado una demanda artificial fomentada en base a recursos públicos muestran que las obras de artistas no evaluados por los intermediarios acaban teniendo el valor del material en el que están elaborados, es decir cercano a cero, y difícilmente consiguen profesionalizarse en el campo artístico (Menger, 2009).
Así pues, desde la invención del sistema críticomarchante a finales del siglo XIX, sustituyendo a los mecanismos académicos de entrada y desarrollo de la carrera artística, los intermediarios han ejercido dos roles fundamentales: por un lado ejercen de porteros o gatekeepers de los mundos artísticos, reduciendo el exceso de oferta, que es uno de las características de las profesiones creativas (Menger, 1999), y por otro lado pueden ejercer diversos tipos de roles dentro de los mercados artísticos: una primera promoción inicial, un desarrollo de la carrera en el ámbito regional o estatal, y finalmente la consagración institucional y la proyección en el mercado global. A cada uno de estas fases de la carrera le corresponderá una tipología de intermediarios con unas competencias y una capacidad económica diferente (Moulin, 1983; Moulin y Cardinal, 2012). Además, al situarse en un polo del mercado artístico o en un segmento del mercado, los intermediarios orientan al consumidor hacia un tipo de oferta. Una orientación que puede ser interpretada como una homología estructural, como una reproducción de las jerarquías en el campo artístico hacia el campo social (Bourdieu, 1991) o bien, de una forma menos determinista, como una mediación entre los mundos artísticos y la formación de comunidades de aficionados capaces de desarrollar criterios y experiencias de creación de gusto y valor (Hennion, 2004).

Algunos autores extienden la noción de creatividad y llegan a afirmar que no solo son creativos los autores sino también los intermediarios, pudiendo hablar de gestión creativa (Bilton, 2007). Sin llegar a este extremo, que nos parece inadecuado por su mezcla de nociones como creatividad cultural e innovación en gestión claramente diferenciables, entendemos que los intermediarios tienen una dimensión fundamental en el sistema cultural al permitir obtener a los creadores una visibilidad. Por ejemplo, es conocido que los marchantes de arte organizan el sistema artístico -como es el caso de Daniel Henry Kahnweiler, marchante de arte que contribuyó decisivamente a crear la noción de estilo cubista (Assouline, 1989)- utilizando para ello sus redes sociales, las ferias artísticas y su conformación en distritos artísticos urbanos con los que atraen la atención de los coleccionistas y aficionados al arte (Rius Ulldemolins, 2012). Un rol semejante podemos encontrar en el caso de los productores del sector audiovisual y discográfico que juegan un rol fundamental también en la generación de nuevos estilos y etiquetas musicales que permiten una mayor visibilidad y conexión con los consumidores musicales (Negus, 2002). 


\section{Creadores e intermediarios: un sistema interdependiente}

En los apartados anteriores hemos fundamentado a partir de autores reconocidos y de investigaciones comparadas la importancia de las interacciones sociales en procesos de creación e intermediación cultural. Sin embargo, ante de los procesos que auguran los efectos benéficos de la destrucción de las profesiones y las industrias culturales tal y como las conocemos actualmente, debemos plantear que la esfera cultural es un sistema interdependiente. Diversos autores han planteado la conveniencia de analizar el campo cultural como un sistema de relaciones en el que intervienen diversos agentes que se condicionan mutuamente (Hirsch, 1972).

Finalmente, algunos autores han detectado una tendencia de los sectores culturales a las intersecciones y vínculos existentes entre el sector comercial, el sector del entertainment y el sector artístico informal (Cherbo y Wyszomirski, 2000). Sería fácil encontrar ejemplos de actores que trabajan al mismo tiempo en series televisivas que les aportan recursos y en actividades de teatro comunitario o educación artística que les ofrecen una actividad e ingresos regulares, así como en proyectos más arriesgados de teatro experimental que les aportan aprendizaje y capital cultural dentro de la profesión (Menger, 1997). Así pues, desde este punto de vista, la crisis o la desaparición de las empresas del sector audiovisual también afecta indirectamente a los proyectos comunitarios y educativos y al teatro experimental. Por lo tanto, la transición al paradigma digital y la caída de ingresos de un segmento no solo afecta a este sino al conjunto del sistema cultural, pudiendo reducir la posibilidad futura de desarrollar proyectos innovadores. Por otra parte, debemos recordar también que los intermediarios tienen la misión de apoyar el creador durante el proceso de creación del público para que comprenda y aprecie las nuevas creaciones y de generación de la demanda que permita generar recursos para que el artista pueda dedicarse profesionalmente a su trabajo (Becker, 1984). En ausencia de intermediaciones, el proceso de profesionalización experimentado desde el siglo XIX puede revertirse y convertir las actividades culturales en actividades parasitarias de otras actividades profesionales, como podría ser la docencia. Sin embargo, la dedicación a tiempo parcial reduce de forma decisiva la capacidad de emprender proyectos intensivos en interacciones a corto plazo y el desarrollo de proyectos a largo plazo, de generación de movimientos culturales que exijan una larga inversión de tiempo y de recursos, como el que pueden facilitar los intermediarios a través de salarios como anticipos a las obras y sus derechos de autor (Levine, 2013).

Además, los intermediarios juegan un rol decisivo como representantes del sector cultural en su conjunto. Los intermediarios culturales tienen una larga tradición de organización profesional y sindical, especialmente en los sectores de las artes escénicas y audiovisuales (pero también, aunque en menor medida en las artes visuales), inclusive en países con una cultura política poco proclive a las reivindicaciones sindicales como es Estados Unidos (Martel, 2011).

\section{CREADORES, INTERMEDIARIOS Y CREACIÓN: UN SIS- TEMA INTERDEPENDIENTE}

Hasta este momento hemos establecido que, lejos de ser una actividad individual realizada de forma aislada, la creación es una actividad en buena medida realizada en el marco de unas estructuras y de unos procesos de interacción, en el que la cooperación con los otros agentes que solemos llamar intermediarios es necesaria y va más allá de las relaciones de prestaciones de servicios: implica una colaboración sustantiva y valorizadora (y por lo tanto conformadora del contenido) de la creación. Sin embargo, los condicionantes sociológicos de la creatividad no acaban aquí sino que, desde una perspectiva más meso y macro sociológica, debemos señalar también que la creación se desarrolla en organizaciones y en sistemas sociales que, como señalan Crozier y Friedberg (1982), condicionan, aunque no determinan, la actuación de los agentes que participan en ellos.

Sin embargo, los análisis sociológicos han mostrado cómo existe una relación entre los condicionantes del sistema cultural y la capacidad de creación e innovación de los agentes culturales. Así pues, algunos autores han analizado los cambios en el sistema cultural como producto de diversos factores internos del campo cultural generadores de transformaciones fundamentales en la forma de crear. Por ejemplo, este es el caso del paso del sistema artístico académico al sistema de mercado operado en el siglo XIX, formado no por una evolución estilística sino principalmente por la incapacidad del sistema académico de ofrecer una carrera artística a una población artística creciente y a la demanda cultural de la población urbana (White, 1993). El sistema de mercado ha sido desde entonces un mecanismo en el que intervienen tres agentes independientes pero articulados (creador, intermediario-emprendedor y crítico) que ha acelerado fuertemente la creatividad artística, primero en el for- 
mato de vanguardias organizadas en la primera parte del siglo XX (Moulin, 1983) hasta su debilitación en torno a los años ochenta (Crane, 1987). Actualmente, a pesar de que algunos autores pronosticaron su disolución, asistimos a un proceso de globalización de los sectores artísticos, especialmente en el caso de las artes visuales, en el que otros agentes de alcance internacional (ferias internacionales, casas de subastas, museos transnacionales) potencian nuevas mediaciones y construcciones de las reputaciones artísticas (Quemin, 2013).

En la perspectiva de la producción de la cultura de Peterson (1982), que establece cinco factores que condicionan la creatividad (la legislación, la tecnología, el mercado, la estructura organizativa y las estructuras de carrera profesional), el sistema cultural puede encontrarse en dos situaciones extremas: a) desde los años treinta hasta los años sesenta se observa la existencia de un monopolio de la intermediación y la estabilidad o repetición (en el sector musical antes del 59) o b) desde los años sesenta el surgimiento de una competencia entre intermediarios (nuevas radios, discográficas y agentes musicales independientes) genera un contexto de alta innovación (con una explosión de creatividad y estilos en la música rock y pop). Sin embargo, el mismo Peterson reconoce que desde los ochenta existe una articulación creciente entre grandes conglomerados y compañías independientes, en un proceso que configura un escenario de competición con una menor creatividad del sistema (Peterson y Anand, 2004). Un escenario además alterado por el surgimiento de las grandes empresas tecnológicas y por la laxa regulación de internet respecto a los derechos de autor (Levine, 2013), que sin embargo no ha paralizado una expansión del cine blockbuster y a la vez las series televisivas de calidad en Estados Unidos (Martel, 2011).

Por otra parte, algunos autores han centrado la evolución del análisis de este sistema cultural en su dimensión urbana, en la concentración en las grandes ciudades (Rius Ulldemolins, 2014) y en configuraciones espaciales como la creación de clústeres culturales, englobando con ello la concentración de empresas culturales y creativas, consumo cultural, instituciones culturales y escenas creativas (Zarlenga, Rius Ulldemolins y Rodríguez Morató, 2016), un estudio que puede ser divido en dos grupos. Por una parte, las investigaciones que se centran en las dinámicas de los clústeres creativos (Mommaas, 2004; Rius Ulldemolins, 2014). Estos autores analizan las razones de la concentración de los creadores basándose en variables como el tipo de organización (la lógica del distrito industrial en el contexto de la economía post-fordista), las particularidades del sector cultural (la concentración de la demanda, de las instituciones de formación, el reconocimiento y la difusión) y las lógicas de la "clusterización" cultural (la valoración cultural de la innovación cultural y la polinización transdisciplinar). Por otra parte, otros autores analizan los efectos en el crecimiento económico causado por la concentración de la clase creativa y en su eficiencia económica y social (Florida, 2005; Markusen y Schrock, 2006; Scott, 2007). Sin embargo, la eficacia en términos de creatividad cultural de los clústeres culturales, más allá de los beneficios económicos y profesionales (Rius Ulldemolins, 2014) o bien de la atracción de la atención pública y mediática hacia fenómenos espectaculares y elitistas del consumo cultural (Currid y Williams, 2010; Molotch y Treskon, 2009), queda aún por demostrar de forma efectiva (Rius Ulldemolins y Zarlenga, 2014). En todo caso, nociones cibertuópicas como la polinización cruzada (Moulier-Boutang, 2010), que auguran una cooperación interdisciplinar y una disolución de las fronteras entre cultura, economía y sociedad, y que algunos autores sitúan en este marco urbano (Currid, 2007), no están demostradas en el ámbito cultural a pesar de ser una bonita metáfora, siendo solamente aplicables a determinados movimientos culturales que, como analiza Collins, han sido impulsados por coaliciones y redes de actores compactas y reducidas y no por redes extensas y descentralizadas (Collins y Guillén, 2012).

\section{NUEVAS TECNOLOGÍAS, CREACIÓN CULTURAL Y EL CAMBIO DE LOS SISTEMAS CULTURALES. LA SUPERA- CIÓN DEL DETERMINISMO TECNOLÓGICO}

Los entusiastas de la digitalización cultural, al centrar su argumentación en la oposición productor-consumidor, donde se relativiza el poder de los productores en favor de los consumidores, tienden a ignorar las configuraciones sociales que promueven la creatividad y favorecen el reconocimiento, difícilmente amoldables a la visión ideal de las comunidades virtuales. Las características estructurales propias de la producción cultural especializada, exploradas en el ámbito de la sociología de la cultura por autores diversos como Bourdieu (2002), Collins (2009), Menger (2009), Becker (2008) o DiMaggio (1991), y el papel de los intermediarios culturales en el proceso de producción, distribución y valoración cultural, escapan a los esquemas interpretativos de los teóricos digitales, y dificultan desde nuestro punto de vista la comprensión adecuada de la lógica específica de los campos culturales. 
La idea de la cultura de la convergencia, defendida por Henry Jenkins (2008), es un botón de muestra de esta visión centrada exclusivamente en una determinada relación entre productores y consumidores culturales, situada en el entorno de las tecnologías digitales. La teoría de la convergencia asegura que se están produciendo procesos de confluencia en diversos niveles y que estas tendencias están transformando completamente la lógica de la producción y el consumo cultural. En primer lugar, encontramos una convergencia tecnológica que es el resultado de la digitalización de los contenidos y de la posibilidad de transferirlos a un coste mínimo a distintos formatos y plataformas mediáticas y digitales. En segundo lugar, junto a la convergencia tecnológica se ha producido una convergencia regulatoria, es decir una estrategia de falta de regulación de las redes de comunicación y de las industrias culturales desde mediados de los años noventa. En tercer lugar, se observa una convergencia mediática en el ámbito de los medios de comunicación y de las industrias culturales, que ha supuesto la integración de las empresas y la creación de conglomerados empresariales globales que controlan todas las etapas de la producción cultural, además de estar presentes en ámbitos cada vez más diversificados. Esta tendencia hacia la concentración y la convergencia en los ámbitos tecnológico y empresarial ha sido criticada desde la sociología por algunos autores (McChesney y Schiller, 2003) pero los entusiastas de la digitalización la entienden como parte de un proceso más amplio de democratización y apertura del consumo cultural. Y es que estas formas de convergencia, según Jenkins (Jenkins, 2008), se han dado en el ámbito de la producción cultural y, a pesar de incitar prácticas monopolísticas en el ámbito de las industrias culturales, y por tanto de facilitar el control de la cultura por parte de un número muy reducido de empresas, sus efectos están directamente asociados a una democratización creciente del consumo cultural. En este proceso doble y paradójico los productores han perdido poder a la hora de controlar los usos de la producción cultural, mientras que los consumidores han adquirido un protagonismo que jamás tuvieron en la época dominada por los medios de comunicación de masas. A este respecto, según sus defensores como Deuze (2006), Jenkins (2008) o Bruns (2008), la cultura de la convergencia tiene dos consecuencias fundamentales: a) favorece una cultura participativa en la que los consumidores son incitados a buscar su propia información y a establecer sus propias conexiones entre contenidos diversos, y b) supone una nueva forma de producción cultural en la que los individuos de manera colectiva comparten intereses y experiencias para resolver problemas comunes, para crear recursos colectivos y para reunir información desperdigada en beneficio de la comunidad. Esta nueva forma de producción social se ha denominado inteligencia colectiva (Lévy, 2007), multitudes inteligentes (Rheingold, 2002) o we-think (Leadbeater, 2008). En todos los casos, se trata de formas de organización social espontáneas que reúnen y comparten recursos, informaciones y creaciones a través de las plataformas tecnológicas, logrando así resultados que no podrían alcanzarse mediante esfuerzos individuales.

Algunos autores llegan a sugerir incluso la ruptura definitiva de la distinción entre los productores de objetos culturales y los consumidores, o entre las audiencias y los públicos que consumen esos objetos. Esta transformación lleva a lo que Bruns (2008) denomina produsage (producción-uso), es decir productos culturales que se producen/consumen -no existe ya distinción entre ambos procesos- en un entorno comunitario y en red, en la que la producción adquiere unas características distintivas, que matizan y actualizan la antigua idea del prosumidor de Alvin Toffler (1970). Bruns (2008) asegura que la producción-uso, que sustituye a las antiguas formas de producción y consumo, tiene las siguientes características: a) participación abierta y evaluación comunal, que permite a individuos muy diversos participar en la producción cultural; b) jerarquías fluidas y meritocracia ad-hoc, en la que todos los participantes, independientemente de sus habilidades específicas, tienen la posibilidad de participar, c) producción cultural inacabada, que supone considerar los objetos culturales como objetos en constante construcción por parte de agentes muy diversos, d) propiedad común: los contenidos no pertenecen al autor o al productor sino que forman parte de los bienes comunales accesibles a cualquiera que los demanda (Miller, 2014).

Lo cierto es que las visiones de la cultura digital sobre el empoderamiento del consumidor y la pérdida de influencia de los productores culturales se desarrollan sin tener en cuenta el entramado completo de agentes e intermediarios culturales que componen el campo cultural. Se considera que los procesos de convergencia tecnológica y mediática han dado lugar a una transformación completa de dos agentes básicos: el productor o creador y los consumidores o públicos. Sin embargo, es sorprendente que estas teorías reproduzcan, mediante un determinismo tecnológico de nuevo cuño, las viejas posiciones del determinismo social y tecnológico que quedaron desfasadas y estaban en franca decadencia hasta hace poco tiempo (Menger, 1992). Así pues, el determinismo tecnológico, a pesar de haber sido debatido desde los años sesenta por su pobreza y mecanicismo interpretativo del desarrollo de las industrias culturales en el que se obvian los usos y condicionantes 
sociales (Eco, 1984), ha vuelto para instalarse en un discurso que no diferencia entre el desarrollo tecnológico y la diversidad de efectos sociales y económicos con relación a los intereses y objetivos diferentes a los que pueden servir (DiMaggio, 2014).

Los defensores más entusiastas de los beneficios de la digitalización cultural consideran que las plataformas tecnológicas determinan las dinámicas internas del campo cultural. Esta afirmación se sustenta con dos líneas de argumentación diferentes: en algunos casos, se evita cualquier mención a las estructuras sociales que influyen en la formación y en el funcionamiento de las comunidades virtuales, al considerarse que estas se mantienen al margen de las formaciones tradicionales (este podría ser el caso de las visiones ciberutópicas de Shirky (2008)); en otros casos, se toman en consideración los procesos de monopolización empresarial (es decir, las transformaciones específicas de la estructura económica) pero sin tener el complejo sistema de relaciones sociales que vincula estas estructuras económicas con las dinámicas propias de los campos culturales -sería el caso de autores como Deuze (2006) o Jenkins (2008)-. El objetivo de este tipo de estudios es incidir sobre todo en la libertad del individuo, integrado en el grupo de iguales de la comunidad virtual para producir cultura al margen de los grandes conglomerados empresariales o modificar y adaptar la cultura distribuida por estas organizaciones según la propia voluntad.

Ciertamente las nuevas tecnologías ofrecen -al menos en el plano teórico- nuevas formas de cooperación entre creadores, la utilización de nuevos materiales, tecnologías o temáticas de creación y nuevas formas de valoración y apropiación (nuevas mediaciones) entre la obra y el público (Ariño Villarroya, 2009; DiMaggio, 2014), así como de participación. Sin embargo, si consideramos la esfera cultural como un sistema de interacciones, dependencias, conflictos y cooperaciones, resulta insuficiente basar el análisis de las transformaciones recientes en el colapso de las relaciones entre productores y consumidores, un análisis que además tiende a realzar solamente los efectos positivos del cambio. Los ámbitos de producción cultural especializada responden a lógicas complejas que no dependen solamente de la reunión espontánea de talentos individuales. Por un lado, los creadores producen en unas condiciones muy particulares que no son equiparables a las existentes en otros ámbitos de la sociedad. Y por el otro, el trabajo de los creadores es secundado por todo un colectivo de intermediarios culturales, especializados en tareas muy diversas (vinculadas a la selección, a la promoción y a la valoración cultural) que no pueden obviarse o reducirse a alusiones genéricas al papel de las industrias culturales como conglomerados empresariales. Por tanto, el análisis de la digitalización de la cultura tiene que ir más allá de las distinciones productor-consumidor para centrarse en el sistema de relaciones sociales, establecido en múltiples niveles, que caracteriza a los campos de la cultura (véase tabla 1).

\section{OBSERVACIONES FINALES}

El auge de las nuevas tecnologías facilita ineludiblemente el acceso a la creación cultural y la debilitación de los intermediarios. Este proceso, según el discurso ciberutópico, conlleva la ausencia de barreras a la entrada en el sector cultural y por lo tanto un florecimiento de la creatividad en un mundo en el que los gastos asociados a la copia tienden marginalmente a cero.

Sin embargo, el discurso de la creatividad libre facilitada por la tecnología trae consigo un debilitamiento del papel de los intermediarios, propiciando una vuelta a la no diferenciación de los quehaceres profesionales vinculados a la creación, producción, distribución y difusión de los contenidos culturales. La literatura científica muestra que ello provoca una profunda pérdida de valor añadido de los contenidos artísticos y una disfunción en el proceso de digitalización del sistema cultural.

Por otra parte, veinte años después de la difusión de internet, los escenarios utópicos de democracia cultural parecen no cumplirse y al contrario el análisis de las actuales tendencias en la esfera cultural nos revelan evoluciones inquietantes: mientras las grandes compañías tecnológicas están configurándose como oligopolios y grandes beneficiados de la transición al paradigma digital ${ }^{6}$, los sectores culturales en Europa en general y en el estado español en concreto se hunden en todos los indicadores de creación y empleo ${ }^{7}$. Asimismo, la "salida digital" a la crisis de la cultura parece no confirmarse, al menos en algunos casos. Uno de los ejemplos para augurar un cambio en el patrón de organización en el sistema cultural como la digitalización de la edición da síntomas de no ser lo suficientemente sólido como para ofrecer una alternativa al modelo tradicional: mientras en 2012 los libros auto-publicados en plataformas digitales se elevaban a 4.592, en 2014 esta cifra se redujo a 3.369. En el periodo 2011-2017 la producción de libros en soporte distinto de papel inscritos en ISBN parece crecer en los dos últimos años permaneciendo estable en el resto del periodo (23.869 en 2011, 22.279 en 2015 y 28.433 en 2017 (Estadística de la Edición Española de Libros con ISBN). 
Tabla 1. Concepción humanística de la cultura, concepción ciberutopista de la transición digital y contraste desde la sociología de la cultura ${ }^{5}$

\begin{tabular}{|c|c|c|c|}
\hline & $\begin{array}{l}\text { Concepción humanística de la } \\
\text { cultura }\end{array}$ & $\begin{array}{l}\text { Concepción ciberutopista de } \\
\text { la transición al paradigma } \\
\text { digital }\end{array}$ & Contraste con la sociología de la cultura \\
\hline \multicolumn{4}{|l|}{ CREADORES CULTURALES } \\
\hline Tipo de interacción & $\begin{array}{l}\text { Los mundos culturales } \\
\text { desarrollan formas de } \\
\text { colaboración entre creativos y } \\
\text { se conforman grupos creativos } \\
\text { especialmente en las etapas } \\
\text { iniciales de la carrera. Sin } \\
\text { embargo, en etapas posteriores, } \\
\text { existe una interacción } \\
\text { competitiva por la entrada en el } \\
\text { campo y por la consagración. }\end{array}$ & \begin{tabular}{|l|} 
La cooperación y la \\
reciprocidad se plantean \\
como forma dominante del \\
tipo de interacción vertical, \\
con la fórmula de peer to \\
peer (P2P). La difusión de \\
la tecnología como medio \\
material y como habilidad \\
hace desaparecer las barreras \\
a la interacción en las \\
comunidades creativas.
\end{tabular} & $\begin{array}{l}\text { Las plataformas digitales pueden facilitar las } \\
\text { interacciones cooperativas, pero también se } \\
\text { establece la competencia por captar recursos } \\
\text { (por ejemplo, por medio de crowdfunding). Las } \\
\text { interacciones en el campo cultural se basan } \\
\text { en convenciones disciplinares especializadas } \\
\text { (Becker, 1994; Becker, 2008) y en pautas } \\
\text { organizativas de las profesiones artísticas } \\
\text { que implican un aprendizaje y una valoración } \\
\text { continua. Los lazos débiles no facilitan este } \\
\text { aprendizaje. }\end{array}$ \\
\hline $\begin{array}{l}\text { Marco de la interacción } \\
\text { creativa }\end{array}$ & $\begin{array}{l}\text { Los mundos artísticos son } \\
\text { conformados por grupos de } \\
\text { profesionales, comunidades } \\
\text { de amateurs e instituciones } \\
\text { culturales. Estas se caracterizan } \\
\text { por lazos fuertes, aunque } \\
\text { inestables y cambiantes en } \\
\text { formato de vanguardia, grupo } \\
\text { artístico o escuela disciplinar. }\end{array}$ & $\begin{array}{l}\text { Se conforman comunidades } \\
\text { predominantemente virtuales } \\
\text { agrupando individuos en } \\
\text { red. En estas comunidades } \\
\text { no hay barreras de entrada } \\
\text { ni tampoco de salida, } \\
\text { caracterizándose como un } \\
\text { marco informal y generando } \\
\text { un lazo débil entre sus } \\
\text { miembros. }\end{array}$ & $\begin{array}{l}\text { Los lazos débiles facilitan cooperaciones } \\
\text { puntuales en objetivos concretos y delimitados } \\
\text { (como un sistema operativo o una enciclopedia) } \\
\text { pero no permiten desarrollar movimientos de } \\
\text { cambio creativo disciplinar. Se da la generación } \\
\text { de fenómenos de mutual halo (Collins, 2009; } \\
\text { Collins y Guillén, 2012), la generación de } \\
\text { modas urbanas o bien fenómenos virales sin } \\
\text { acumulación y organización disciplinar. }\end{array}$ \\
\hline Proceso de creación & $\begin{array}{l}\text { Creación por focalización en } \\
\text { unos centros de atención } \\
\text { cultural definidos con un criterio } \\
\text { disciplinar (tipos de obras). La } \\
\text { creación es concebida como } \\
\text { símbolo de excelencia y la } \\
\text { innovación como renovación } \\
\text { disciplinar. La tecnología es } \\
\text { concebida como herramienta } \\
\text { básica. }\end{array}$ & \begin{tabular}{|l|} 
Se concibe la creación \\
de tipo transdisciplinar \\
basada en la abundancia \\
de contribuciones de la \\
multitud. La creación es \\
concebida como contenido \\
sin jerarquización valorativa \\
y la innovación como \\
desarrollo técnico, aumento \\
de conocimiento o expresión \\
del individuo. La tecnología \\
es concebida como impulso a \\
la creación o como parte de \\
la creación.
\end{tabular} & $\begin{array}{l}\text { La digitalización de la cultura ha llevado } \\
\text { al énfasis en la dimensión cooperativa y } \\
\text { participativa de la cultura. Sin embargo, la } \\
\text { creación cultural sigue desarrollándose a } \\
\text { partir de la noción de autoría y en el marco de } \\
\text { organizaciones formales, siendo una excepción } \\
\text { los fenómenos de creación transdisciplinar. } \\
\text { La tecnología puede facilitar la creación, pero } \\
\text { no supone de por si una democratización de } \\
\text { su uso. La tecnología no puede sustituir a los } \\
\text { rituales e interacciones del proceso creativo } \\
\text { (Becker, 2008; Collins, 2009). }\end{array}$ \\
\hline Incentivo a la creación & $\begin{array}{l}\text { Reconocimiento público e } \\
\text { institucional, premios, inclusión } \\
\text { en el canon cultural (inclusión } \\
\text { en la memoria cultural y en } \\
\text { los panteones nacionales). } \\
\text { Asimismo, a partir del } \\
\text { reconocimiento se produce a } \\
\text { medio y largo plazo un éxito } \\
\text { económico a partir de las ventas } \\
\text { sostenidas. }\end{array}$ & \begin{tabular}{|l|} 
No existe directamente un \\
incentivo a la creación más \\
que el reconocimiento de la \\
comunidad o el éxito viral \\
en las redes sociales. El \\
éxito económico se produce \\
a partir de una demanda \\
dispersa (long tail) y no tanto \\
a partir de un éxito masivo.
\end{tabular} & $\begin{array}{l}\text { El incentivo a la creación es la participación } \\
\text { en el juego o la illusio del campo (Bourdieu, } \\
\text { 2002), la generación de rituales o de } \\
\text { constantes evaluaciones por parte de los } \\
\text { pares o el mercado. Los incentivos débiles del } \\
\text { ciberutopismo generan también compromisos } \\
\text { débiles e intermitentes poco adecuados para } \\
\text { la creación de proyectos creativos y nuevos } \\
\text { estilos. Asimismo, la transición al paradigma } \\
\text { digital incentiva el oportunismo creativo } \\
\text { dirigido a la reproducción viral. }\end{array}$ \\
\hline Mecanismo de selección & $\begin{array}{l}\text { No existe barrera formal a la } \\
\text { entrada en el mundo artístico. } \\
\text { Sin embargo, los individuos se } \\
\text { seleccionan por los maestros y } \\
\text { los compañeros en primer lugar } \\
\text { según su talento, que puede } \\
\text { ser concebido como innato o } \\
\text { como fruto del aprendizaje y la } \\
\text { práctica. Existe una elite muy } \\
\text { visible y valorada que conforma } \\
\text { la imagen del artista-genio. }\end{array}$ & $\begin{array}{l}\text { El mecanismo de selección } \\
\text { se basa en la relevancia de } \\
\text { la contribución según la } \\
\text { comunidad participativa. } \\
\text { Se produce un rechazo } \\
\text { del establecimiento de } \\
\text { mecanismos formales de } \\
\text { selección; sin embargo, } \\
\text { existen reputaciones } \\
\text { cualitativas y cuantitativas } \\
\text { a partir de las evaluaciones } \\
\text { de los pares y de los } \\
\text { consumidores de forma } \\
\text { habitualmente anónima o } \\
\text { bajo seudónimos. }\end{array}$ & $\begin{array}{l}\text { Existen de facto mecanismos sociales que } \\
\text { explican una diferente participación de los } \\
\text { individuos y la generación del carisma del } \\
\text { artista (Menger, 2009). No obstante, la ausencia } \\
\text { de selección a la entrada (gatekeepers) y de } \\
\text { filtros ? lincentivos- o criterios de promoción } \\
\text { en sucesivas etapas de la carrera creativa } \\
\text { puede generar una falta de capacidad de } \\
\text { profesionalización y una competencia creciente } \\
\text { entre los creadores. Finalmente la atomización } \\
\text { de la creación es poco compatible con la } \\
\text { creación de un foco creativo. }\end{array}$ \\
\hline
\end{tabular}




\begin{tabular}{|c|c|c|c|}
\hline Rol de los intermediarios & $\begin{array}{l}\text { La función del intermediario es la } \\
\text { de selección en la entrada en el } \\
\text { sector cultural (gatekeeper), la de } \\
\text { dar soporte material al creador } \\
\text { y la de contribuir a reconocer } \\
\text { el valor de la obra de arte. La } \\
\text { valoración de las creaciones } \\
\text { por parte de los intermediarios } \\
\text { se basa en su aportación al } \\
\text { desarrollo disciplinar. }\end{array}$ & $\begin{array}{l}\text { La desaparición de los } \\
\text { intermediaros profesionales } \\
\text { y especializados produce la } \\
\text { ausencia de barreras para } \\
\text { la creación y por lo tanto la } \\
\text { abundancia de producción y } \\
\text { consumo cultural. Por otra } \\
\text { parte, surgen intermediarios } \\
\text { genéricos como } \\
\text { descubridores de tendencias } \\
\text { o modas. }\end{array}$ & $\begin{array}{l}\text { La ausencia de intermediarios puede provocar } \\
\text { un aumento de la producción cultural a corto } \\
\text { plazo pero un estancamiento en la creatividad } \\
\text { y en la capacidad de desarrollo de carreras } \\
\text { artísticas. Los intermediarios pierden capacidad } \\
\text { para apostar por la innovación y apuestan por } \\
\text { creadores consagrados. En este proceso ganan } \\
\text { los intermediarios híbridos que conectan las } \\
\text { esferas culturales con la económica (branding } \\
\text { empresarial, publicidad, marketing) o con la } \\
\text { esfera académica o de consultoría (ensayistas, } \\
\text { gurús). Finalmente, esta debilitación somete } \\
\text { a los creadores a una mayor presión frente a } \\
\text { los consumidores y a un mayor control de la } \\
\text { industria y los media (Bourdieu, 2002). }\end{array}$ \\
\hline $\begin{array}{l}\text { Valoración de las } \\
\text { contribuciones }\end{array}$ & $\begin{array}{l}\text { El reconocimiento se produce } \\
\text { a largo y medio plazo a través } \\
\text { del aumento del precio (cota } \\
\text { o caché) y a partir de rituales } \\
\text { o posiciones institucionales } \\
\text { (premios o cargos prestigiosos). }\end{array}$ & $\begin{array}{l}\text { La valoración de las } \\
\text { contribuciones no } \\
\text { la desarrollan los } \\
\text { intermediarios, sino que se } \\
\text { realiza por su dimensión } \\
\text { cuantitativa (a través de } \\
\text { mecanismos de inteligencia } \\
\text { colectiva) o bien por } \\
\text { evaluaciones de su impacto } \\
\text { social desarrolladas por las } \\
\text { plataformas tecnológicas. }\end{array}$ & $\begin{array}{l}\text { La transición al paradigma digital facilita a los } \\
\text { usuarios convertirse en intermediarios. Sin } \\
\text { embargo, la debilitación de los intermediarios } \\
\text { profesionales y de su rol de selección y } \\
\text { valoración de forma independiente y en } \\
\text { concurrencia con otros agentes facilita que } \\
\text { las evaluaciones sean desarrolladas o bien } \\
\text { por grandes corporaciones o bien a partir de } \\
\text { fenómenos virales. }\end{array}$ \\
\hline $\begin{array}{l}\text { Segmentación de la } \\
\text { demanda }\end{array}$ & $\begin{array}{l}\text { El sector cultural se divide en } \\
\text { una demanda segmentada según } \\
\text { el nivel cultural: una demanda } \\
\text { de horizonte masivo y bajo } \\
\text { nivel cultural y otra dirigida a la } \\
\text { minoría entendida y de alto nivel } \\
\text { cultural. }\end{array}$ & \begin{tabular}{|l|} 
La oferta cultural se \\
diversifica eliminando una \\
segmentación clara por \\
nivel y los consumidores \\
desarrollan una diversidad de \\
gustos independientemente \\
de la oferta de la industria \\
cultural. Los mecanismos \\
tecnológicos permiten hacer \\
viables las audiencias muy \\
segmentadas basadas en \\
comunidades.
\end{tabular} & $\begin{array}{l}\text { Existe una falta de sistematización de la oferta } \\
\text { y una predisposición al consumo de bienes } \\
\text { culturales cualesquiera en la demanda, lo } \\
\text { que dibuja una oferta más segmentada. } \\
\text { Sin embargo, el debilitamiento de los } \\
\text { intermediarios disminuye la capacidad del } \\
\text { sector cultural de generar una demanda nueva } \\
\text { para las innovaciones creativas y aunque } \\
\text { permite el surgimiento de comunidades } \\
\text { facilitadas por las nuevas tecnologías, estas } \\
\text { se desarrollan en torno a productos y marcas } \\
\text { generadas por las industrias culturales. }\end{array}$ \\
\hline Objetivo como sistema & $\begin{array}{l}\text { El objetivo del sector cultural es } \\
\text { el desarrollo de las artes como } \\
\text { expresión de la subjetividad del } \\
\text { genio artístico y a la vez como } \\
\text { fuente de progreso colectivo. }\end{array}$ & $\begin{array}{l}\text { El objetivo del sistema } \\
\text { cultural es el desarrollo } \\
\text { de bienes comunes (ni } \\
\text { privados ni públicos) a } \\
\text { partir de la puesta en } \\
\text { común de contenidos } \\
\text { culturales. Asimismo, la } \\
\text { cultura tiene un impacto } \\
\text { derivado de la participación } \\
\text { en la producción cultural a } \\
\text { partir de la participación en } \\
\text { comunidades de creación. }\end{array}$ & $\begin{array}{l}\text { Efectivamente la participación en las } \\
\text { artes supone una modificación de los } \\
\text { comportamientos y el surgimiento de nuevas } \\
\text { identidades y comunidades. Sin embargo, } \\
\text { este proceso puede derivar también en } \\
\text { la generación de identidades ancladas en } \\
\text { lo estético y en la debilitación de lazos de } \\
\text { solidaridad en el marco nacional o regional. }\end{array}$ \\
\hline $\begin{array}{l}\text { Concepción de la autoría } \\
\text { y su protección }\end{array}$ & $\begin{array}{l}\text { La noción de autoría se } \\
\text { fundamente en la idea de la } \\
\text { creatividad individual basada } \\
\text { en el genio y esfuerzo del } \\
\text { creador. Los derechos de autor } \\
\text { suponen su reconocimiento } \\
\text { y su protección frente a } \\
\text { los intermediarios y los } \\
\text { consumidores. }\end{array}$ & \begin{tabular}{|l|} 
La posición ciberutópica \\
niega la noción de autoría y \\
la concibe como producto \\
de la copia y como producto \\
de la creatividad de la \\
multitud. Propone el libre \\
acceso a todos los contenidos \\
con independencia de la \\
voluntad del autor o bien \\
a partir de la renuncia del \\
autor a los derechos de \\
autor o copyright (creative \\
commons).
\end{tabular} & $\begin{array}{l}\text { Los estudios indican una inadaptación de } \\
\text { los derechos de autor en el marco de la } \\
\text { digitalización de la cultura, especialmente por } \\
\text { una excesiva extensión durante generaciones } \\
\text { y por la regulación nacional de un fenómeno } \\
\text { global. Sin embargo, la violación o renuncia de } \\
\text { los derechos de autor sitúa en una posición } \\
\text { de debilidad socio-económica a autores } \\
\text { y a intermediarios, frente a los agentes } \\
\text { tecnológicos que se benefician de su difusión } \\
\text { en sus canales (buscadores, plataformas, etc.). }\end{array}$ \\
\hline
\end{tabular}




\begin{tabular}{|c|c|c|c|}
\hline $\begin{array}{l}\text { Sistema de distribución } \\
\text { y financiación del } \\
\text { sistema }\end{array}$ & $\begin{array}{l}\text { La distribución y la financiación } \\
\text { del sector cultural se obtienen } \\
\text { mediante una combinación } \\
\text { de donaciones individuales y } \\
\text { empresariales, de subvenciones } \\
\text { estatales, del mercado en } \\
\text { el segmento vanguardista e } \\
\text { institucional y mediante la venta } \\
\text { al público en el segmento de las } \\
\text { industrias culturales. }\end{array}$ & \begin{tabular}{|l|} 
Las plataformas digitales \\
constituyen una forma de \\
distribución indistinta para las \\
producciones profesionales \\
vanguardistas, institucionales, \\
mercantiles y para la cultura \\
amateur. La financiación \\
del sistema cultural se debe \\
basar en la financiación \\
colectiva o micro-mecenazgo.
\end{tabular} & $\begin{array}{l}\text { La conversión de los sistemas de distribución } \\
\text { cultural por parte de las grandes empresas } \\
\text { tecnológicas en oligopolios, junto con la } \\
\text { debilidad de los autores e intermediarios } \\
\text { por la digitalización, crea una situación de } \\
\text { fragilidad del sistema creativo. La disminución } \\
\text { del mercado y las subvenciones, la drástica } \\
\text { disminución de ingresos por derechos de } \\
\text { autor o actuaciones en directo, junto con el } \\
\text { escaso volumen de mecanismos emergentes } \\
\text { (crowdfunding) sitúa el sector cultural en una } \\
\text { crisis sistémica. }\end{array}$ \\
\hline $\begin{array}{l}\text { Conservación de las } \\
\text { creaciones }\end{array}$ & $\begin{array}{l}\text { Las instituciones culturales } \\
\text { públicas o privadas sin ánimo } \\
\text { de lucro tienen la misión de la } \\
\text { de conservación y la valoración } \\
\text { del patrimonio. Su selección de } \\
\text { obras y autores crea los cánones } \\
\text { disciplinares. }\end{array}$ & $\begin{array}{l}\text { La conservación de los } \\
\text { contenidos culturales sin } \\
\text { distinción de orígenes debe } \\
\text { almacenarse en repositorios } \\
\text { digitales de libre acceso. }\end{array}$ & $\begin{array}{l}\text { Los repositorios de la cultura digital, si bien en } \\
\text { algunos casos son de acceso libre actualmente } \\
\text { y pueden aumentar el acceso a la cultura y el } \\
\text { conocimiento, en gran parte son propiedad } \\
\text { de grandes empresas privadas que se lucran } \\
\text { con la publicidad, los datos acumulados y los } \\
\text { servicios de acceso. La falta de selección en } \\
\text { la conservación de las creaciones desactiva la } \\
\text { innovación basada en la innovación disciplinar } \\
\text { e incrementa el peso de los fenómenos } \\
\text { efímeros y virales, debilitando la autonomía de } \\
\text { la esfera cultural. }\end{array}$ \\
\hline
\end{tabular}

Fuente: elaboración propia a partir de la bibliografía citada.

Ciertamente el desarrollo y la base empírica del presente artículo no nos permite de momento desarrollar unas conclusiones cerradas sobre la pregunta inicial planteada: si la transición al paradigma digital está fomentando o perjudicando la creatividad o más concretamente cómo está afectando a la generación, la valoración y la comprensión de la creatividad. Sin embargo, entendemos que este artículo permite una primera fase de la reflexión sociológica: la ruptura epistemológica y la construcción del objeto de estudio. A partir de esta base se podrá avanzar en un análisis más equilibrado y neutral sobre la digitalización del sector cultural, un fenómeno que avanza a gran velocidad y que obligará a las ciencias sociales a desarrollar nuevas teorías, conceptos, herramientas metodológicas e investigaciones para comprenderlo.

\section{NOTAS}

1. Así como la noción de cultura digital alude a una realidad sustantiva y constituida, la idea de la digitalización del campo cultural incide en que la digitalización es un proceso que se produce dentro del campo cultural y que actúa en consonancia con otros procesos paralelos que pueden ser incluso opuestos a la lógica digital. Por otra parte, este proceso no afecta de igual manera a los distintos campos artísticos. Algunos sectores como las artes escénicas, dada la naturaleza de la exhibición en vivo, son más o menos propicios a la digitalización que otros sectores como los industriales. Entre estos últimos la tasa de digitalización (porcentaje sobre el total de la facturación de cada sector) de algunos en 2011 también presenta diferencias: en la música es del 55,8 \%, en el cine y en el video es del $73,2 \%$, llegando al 90,5\% en el sector audiovisual (Informe Anual "La Sociedad en Red" 2011). No obstante, esta tendencia al- cista se mantiene estable en las cifras de negocio de los contenidos culturales. Así, en los últimos años, en el caso de los contenidos musicales se estabiliza (340 millones de euros en 2011 y 341 en 2016) o desciende en el sector de libro, periódicos y otras publicaciones $(6.782$ millones de euros en 2011 y 5.676 en 2016), si bien se mantiene en alza en el caso en los contenidos cinematográficos y de televisión (4.021 millones de euros en 2011 y 4.646 en 2016) (Informe Anual "La Sociedad en Red" 2017).

2. En este artículo tomaremos la noción de intermediario cultural en el sentido restringido, es decir, como 'agente del sector cultural', como hacen diversos estudios recientes (Lapierre y Roueff, 2013) y no en términos macro-sociológicos como 'transmisor o manipulador de elementos simbólicos culturales', como lo hacen otros autores (Featherstone 2000), una noción que, si bien introduce elementos de interés para comprender el sector cultural, desborda e introduce confusión en el objeto de este artículo.

3. En este artículo descartamos asimismo el enfoque también sociológico que se centra en los procesos sociales participativos. Csikszentmihalyi (1998) distinguió entre big $C$, la creatividad objetivamente reconocida, en contraposición a la small c, una creatividad que pertenece a la vida cotidiana. La sociología también estudia esta dimensión privada y ordinaria de la creatividad en los procesos sociales tales como las artes comunitarias (Webster y Buglass, 2005; Thornham, 2014) o incluso en los procesos de investigación-acción.

4. La defensa de la desaparición de los intermediarios culturales por parte de unas posturas que parten de posiciones políticas progresistas o de izquierdas es en gran medida paradójica al afectar también en este sentido la capacidad 
de los asalariados y profesionales de formular colectivamente los intereses dentro del sector cultural frente a las grandes compañías de producción de contenidos o de las multinacionales tecnológicas. De hecho, hay que entender que la defensa de la desaparición de los intermediaros culturales forma parte del carácter libertario y neoliberal de la ideología californiana (Barbrook y Cameron, 1996).

5. Para construir la tabla hemos partido de la bibliografía analizada y citada a lo largo del artículo. En el caso de la concepción humanística hemos partido de la definición humanística de la cultura de Ariño (1997) y de los análisis de Bourdieu (2002) sobre el desarrollo del

\section{BIBLIOGRAFÍA}

Ariño Villarroya, A. (1997). Sociología de la cultura: la constitución simbólica de la sociedad. Barcelona: Ariel.

Ariño Villarroya, A. (2009). El movimiento open: la creación de un dominio público en la era digital. València: Universitat de València.

Assouline, P. (1989). L'Homme de l'art. D.-H. Kahnweiler (1884-1979). Paris: Gallimard.

Barbrook, R. y Cameron, A. (1996). The Californian Ideology. Science as Culture, 26 (1), pp. 44-72. https://doi. org/10.1080/09505439609526455

Becker, H. S. (1984). Art Worlds. Berkeley: University of California Press.

Becker, H. S. (1994). La confusion des valeurs. En Menger, P.-M. y Passeron, J-C. (eds.). L'art de la recherche. Essais en I'honneur de Raymonde Moulin. Paris: La Documentation française, pp. 24-39.

Becker, H. S. (2008). Los mundos del arte. Sociología del trabajo artístico. Buenos Aires: Universidad Nacional de Quilmes.

Bell, D. (1991). El advenimiento de la sociedad post-industrial: un intento de prognosis social. Madrid: Alianza.

Bilton, C. (2007). Management and creativity: from creative industries to creative management. Malden, Oxford: Blackwell.

Bourdieu, P. (1977). La production de la croyance. Contribution à une économie des biens symboliques. Actes de campo artístico en el siglo XIX y XX. Con relación a la concepción ciberutopista, hemos revisado un amplio espectro de bibliografía de tipo académico o ensayístico sobre la llamada cultura digital (Bruns, 2008; Coleman, 2013; Deuze, 2006; Jenkins, 2008; Lévy, 2007; Shirky, 2008). Finalmente, en la columna de contraste con las aportaciones de la sociología y su aplicación al análisis del proceso de la transición al paradigma digital debemos citar a diversos autores como Bourdieu (2002), Becker (2008), Collins (2009) y Collins y Guillén (2012).

6. Amazon, Google, Apple y Yahoo facturaron en 2012 unos 160.000 millones de euros, seis veces más que los grandes conglomerados editoriales. Asimismo,

la Recherche en Sciences Sociales, 13 (1), pp. 3-43. https://doi.org/10.3406/ arss.1977.3493

Bourdieu, P. (1991). La distinción: criterios y bases sociales del gusto. Madrid: Taurus.

Bourdieu, P. (1997). Sobre la televisión. Barcelona: Anagrama.

Bourdieu, P. (2002). Las reglas del arte: génesis y estructura del campo literario. Barcelona: Anagrama.

Bruns, A. (2008). Blogs, Wikipedia, Second Life and beyond: from production to produsage. Nueva York: Peter Lang.

Cherbo, J. M. y Wyszomirski, M. J. (2000). The public life of the arts in America. New Brunswick N.J.: Rutgers University Press.

Coleman, G. (2013). Coding freedom: the ethics and aesthetics of hacking. Nueva Jersey: Princeton University Press.

Collins, R. (1987). A micro-macro theory of intellectual creativity: The case of German idealist philosophy. Sociological Theory, 5 (1), pp. 47-69. https://doi. org/10.2307/201995

Collins, R. (1989). Toward a Theory of Intellectual Change: The Social Causes of Philosophies. Science, Technology, \& Human Values, 14 (2), pp. 107-140. https:// doi.org/10.1177/016224398901400201

Collins, R. (2005). Sociología de las filosofias: una teoría global del cambio intelectual. Barcelona: Hacer.
Amazon y Apple en 2012 concentraron el $70 \%$ de las descargas digitales globales de música y libros (Levine 2013).

7. Según los datos del Anuario de la Sociedad General de Autores Españoles (SGAE) podemos observar los siguientes descensos en los sectores culturales: a) artes escénicas: pérdidas del 30,4\% (representaciones), del 34,3\% (asistencia), 23\% (recaudación) entre 2009-2014 (Anuario SGAE de las Artes Escénicas, Musicales y Audiovisuales. 2015); b) en música: descensos del 25,5\% (conciertos) al 33,2\% (asistencia) y al 19,2\% (recaudación) entre 2009-2014; c) libros: $29,8 \%$ de descenso en la facturación y $34,9 \%$ en la venta de ejemplares ( $E$ / sector del libro en España 2012-2014).
Collins, R. (2009). Cadenas de rituales de interacción. Barcelona: Anthropos.

Collins, R. y Guillén, M. F. (2012). Mutual halo effects in cultural production: the case of modernist architecture. Theory and Society, 41 (6), pp. 527-556. https:// doi.org/10.1007/s11186-012-9181-9

Crane, D. (1987). The transformation of the Avant-Garde: the New York Art World,1940-1985. Chicago: The University of Chicago Press.

Crozier, M. y Friedberg, E. (1982). L'Acteur et le système : les contraintes de l'action collective. Paris: Éditions du Seuil.

Csikszentmihalyi, M. (1998). Reflections on the field. Roeper Review: A Journal on Gifted Education, 21 (1), pp. 80-81.

Currid, E. (2007). The Warhol economy: how fashion, art, and music drive New York City. Princeton University Press.

Currid, E. y Williams, S. (2010). The geography of buzz: art, culture and the social milieu in Los Angeles and New York. Journal of Economic Geography, 10 (3), pp. 423451. https://doi.org/10.1093/jeg/lbp032

DeNora, T. (1995). Beethoven and the Construction of Genius: Musical Politics in Vienna, 1792-1803. Los Angeles: University of California Press.

Deuze, M. (2006). Participation, remediation, bricolage: considering principal components of a digital culture. The Information Society, 22 (2), pp. 63-75. https://doi. org/10.1080/01972240600567170 
DiMaggio, P. (1991). Social Structure, Institutions and Cultural Goods: The Case of the United States. En Bourdieu, P. y Coleman, J. S. (eds.). Social Theory for a Changing Society. Boulder: Westview Press, pp. 133-166.

DiMaggio, P. (2000). The production of the scientific change. Richard Peterson and the institutional turn in cultural sociology. Poetics, 28 (2-3), pp. 107136. https://doi.org/10.1016/S0304422X(00)00017-6

DiMaggio, P. (2014). La influencia de internet en la producción y el consumo de cultura. destrucción creativa y nuevas oportunidades. En Benkler et al. C@ mbio. 19 ensayos fundamentales sobre cómo internet está cambiando nuestras vidas. Madrid: Open Mind / BBVA / Turner, pp. 359-396.

Donzelot, J., Walkowitz, J. R., Parker, I., Varela, J., Burman, E. y Pastor, J. (2007). La fragilización de las relaciones sociales. Madrid: Círculo de Bellas Artes.

Eco, U. (1984). Apocalípticos e integrados. Barcelona: Lumen.

Elías, N. (2002). Mozart. Sociología de un genio. Madrid: Península.

Featherstone, M. (2000). Cultura de consumo y posmodernismo. Buenos Aires: Amorrortu.

Florida, R. L. (2005). Cities and the creative class. Routledge. https://doi. org/10.4324/9780203997673

Franck, D. (2003). Bohemian Paris: Picasso, Modigliani, Matisse, and the Birth of Modern Art. Nueva York: Grove Press.

Granovetter, M. S. (1973). The Strength of Weak Ties. The American Journal of Sociology, 78 (6), pp. 1360-1380. https:// doi.org/10.1086/225469

Heinich, N. (1992). La gloire de Van Gogh. Essai d'anthropologie de l'admiration. Paris: Éditions de Minuit.

Hennion, A. (2004). Une sociologie des attachements. D'une sociologie de la culture à une pragmatique de l'amateur. Sociétés, 85 (3), pp. 9-24. https://doi. org/10.3917/soc.085.0009

Hirsch, P. M. (1972). Processing Fads and Fashions: An Organization-Set Analysis of Cultural Industry Systems. American Journal of Sociology, 77 (4), pp. 639-659. https://doi. org/10.1086/225192
Jenkins, H. (2008). Convergence culture. La cultura de la convergencia de los medios de comunicación. Barcelona, Buenos Aires, México: Paidós.

Lanier, J. (2010). You Are Not a Gadget: A Manifesto. New York: Alfred A. Knopf.

Lapierre, L. y Roueff, O. (dirs.) (2013). La culture et ses intermédiaires. Dans les arts, le numérique et les industries créatives. Strasbourg: Éditions des Archives Contemporaines.

Leadbeater, C. (2008). We-think. Mass innovation, not mass production. Londres: Profile Books.

Lessig, L., A. Córdoba y Candeira, J. (2005). Por una cultura libre: cómo los grandes grupos de comunicación utilizan la tecnología y la ley para clausurar la cultura y controlar la creatividad. Madrid: Traficantes de Sueños.

Levine, R. (2013). Parásitos. Cómo los oportunistas digitales están destruyendo el negocio de la cultura. Barcelona: Ariel.

Lévy, P. (2007). Cibercultura. La cultura de la sociedad digital. México: Anthropos.

Markusen, A. y Schrock, G. (2006). The Artistic Dividend: Urban Artistic Specialisation and Economic Development Implications. Urban Studies, 43 (10), pp. 1661-1686. https://doi. org/10.1080/00420980600888478

Martel, F. (2011). Cultura Mainstream. Como nacen los fenómenos de masas. Madrid: Taurus.

McChesney, R. y Schiller, D. (2003). The Political Economy of International Communications. Foundations for the Emerging Global Debate about Media Ownership and Regulation. United Nations Research Institute for Social Development. Technology, Business and Society. Programme Paper Number 11. [En línea]. Disponible en http://www. unrisd.org/80256B3C005BCCF9/(httpAuxPages)/c9dcba6c7db78c2ac1256b df0049a774/\$file/mcchesne.pdf

Menger, P.-M. (1992). Les paradigmes de la sociologie de l'art. En Domínguez, I. y Rodríguez Morató, A. (comps.). Arte, cultura y sociedad. Bilbao: Aesca, pp. 42-57.

Menger, P.-M. (1997). La profession de comédien : formations, activités et carrières dans la démultiplication de soi. Paris: Ministère de la Culture et de la Communication. Département des études et de la prospective.
Menger, P.-M. (1999). Artistic Labor Markets and Careers. Annual Review of Sociology, 25 (1), pp. 541-574. https://doi. org/10.1146/annurev.soc.25.1.541

Menger, P.-M. (2009). Les professions artistiques et leurs inégalités. En Demaziêre , D. y Gadéa, Ch. (dirs.) Sociologie des groupes professionnels. Acquis récents et nouveaux défis. Paris: La Découverte, pp. 355-366.

Miller, V. (2014). Understanding digital culture. London: Sage.

Molotch, H. y Treskon, M. (2009). Changing Art: SoHo, Chelsea and the Dynamic Geography of Galleries in New York City. International Journal of Urban and Regional Research, 33 (2), pp. 517-541. https://doi. org/10.1111/j.1468-2427.2009.00866.x

Mommaas, H. (2004). Cultural clusters and the post-industrial city: towards a remapping of urban cultural policy. Urban Studies, 41 (3), pp. 507-532. https://doi. org/10.1080/0042098042000178663

Morozov, E. (2012). El Desengaño de internet. Los mitos de la libertad en la red. Barcelona: Destino.

Morozov, E. (2013). To save everything, click here. New York: PublicAffairs.

Moulier-Boutang, Y. (2010). L'abeille et l'économiste. Paris: Éditions Carnets Nord.

Moulin, R. (1983). Le marché de l'art en France. Paris: Éditions de Minuit.

Moulin, R. (1992). L'artiste, l'institution et le marché. Paris: Flammarion.

Moulin, R. y Cardinal, M. (2012). El mercado del arte. Mundialización y nuevas tecnologías. Buenos Aires: La Marca.

Negus, K. (2002). The work of cultural intermediaries and the enduring distance between production and consumption. Cultural Studies, 16 (4), pp. 501-515. https://doi. org/10.1080/09502380210139089

Pecourt, J. (2007). El intelectual y el campo cultural. Una variación sobre Bourdieu. Revista Internacional de Sociología, 65 (47), pp. 23-43.

Peterson, R. A. (1982). Five Constraints on the Production of Culture: Law, Technology, Market, Organizational Structure and Occupational Careers. The Journal of Popular Culture, 16 (2), pp. 143153. https://doi.org/10.1111/j.00223840.1982.1451443.x 
Peterson, R. A. (1997). Creating country music. Fabricating authenticity. Chicago: University of Chicago Press. https://doi.org/10.7208/chicago/9780226111445.001.0001

Peterson, R. A. y Anand, N. (2004). The production of culture perspective. Annual Review of Sociology, 30, pp. 311334. https://doi.org/10.1146/annurev. soc.30.012703.110557

Putnam, R. D. 2000. Bowling Alone: The Collapse and Revival of American Community. New York: Simon and Schuster.

Quemin, A. (2013). Les stars de l'art contemporain. Notoriété et consécration artistiques dans les arts visuels. Paris: CNRS Editions.

Rendueles, C. (2013). Sociofobia. El cambio político en la era de la utopía digital. Madrid: Capitán Swing.

Rheingold, H. (2002). Smart mobs. The next social revolution. New York: Basic Books.

Rius Ulldemolins, J. (2012). Gallery districts of Barcelona: the strategic play of art dealers. The Journal of Arts Management, Law and Society, 42 (2), pp. 4862. https://doi.org/10.1080/10632921. 2012.678929

Rius Ulldemolins, J. (2014). ¿Por qué se concentran los artistas en las grandes ciudades? Factores infraestructurales de localización, estrategias profesionales y dinámicas comunitarias. Revista Española de Investigaciones Sociológicas (REIS), 147 (1), pp. 73-88.

Rius Ulldemolins, J. (2015). Contra el ciberutopismo. Discurso utópico versus análisis sociológico sobre la transición al paradigma digital de la esfera cultural. Politica y Sociedad, 52 (1), pp. 153-178.
Rius Ulldemolins, J. y Zarlenga, M. (2014). Industrias, distritos, instituciones y escenas. Tipología de clústeres culturales en Barcelona. Revista Española de Sociología, 21, pp. 47-68.

Rubio Arostegui, J. A., Rius Ulldemolins, J. y Martinez IIla, S. (2014). El modelo español de financiación de las artes y la cultura en el contexto europeo. Crisis económica, cambio institucional, gobernanza y valor público de la cultura y la política cultural. Madrid: Fundación Alternativas.

Scott, A. (2007). Capitalism and Urbanization in a New Key? The Cognitive-Cultural Dimension. Social Forces, 85 (4), pp. 1465-1482. https://doi.org/10.1353/ sof. 2007.0078

Shirky, C. (2008). Here Comes Everybody: The Power of Organizing Without Organizations. New York: Penguin Press.

Thornham, H. (2014). Claiming 'creativity': discourse, 'doctrine' or participatory practice? International Journal of Cultural Policy, 20 (5), pp. 536-552. https://doi. org/10.1080/10286632.2013.865729

Toffler, A. (1970). Future Shock. New York: Random House.

Webster, M. y Buglass, G. (2005). Finding voices, making choices: creativity for social change. Nottingham: Educational Heretics Press.

White, H. C. (1993). Careers and creativity: social forces in the arts. Colorado: Westview Press.

Williams, R. (1994). Sociología de la cultura. Barcelona, Buenos Aires, México: Paidós.

Williams, R. (2001). Cultura y sociedad 1780-1950. De Coleridge a Orwell. Buenos Aires: Nueva Visión.
Zarlenga, M. I., Rius Ulldemolins, J. y Rodríguez Morató, A. (2016). Cultural clusters and social interaction dynamics: The case of Barcelona. European Urban and Regional Studies, 23 (3), pp. 422-440. https://doi. org/10.1177/0969776413514592

\section{Otros recursos}

Anuario SGAE de las Artes Escénicas, Musicales y Audiovisuales. 2015. [En línea]. Disponible en http://gesculcyl.org/ anuario-sgae-de-las-artes-escenicasmusicales-y-audiovisuales/

El sector del libro en España 2012-2014. Madrid: Observatorio de la Lectura y el Libro. Ministerio de Educación, Cultura y Deporte. Abril 2014. [En línea]. Disponible en http://www.culturaydeporte.gob. es/dam/jcr:7a6a7251-f243-4b71-8a9c27db84c90533/sectorlibro-abril2014.pdf

Estadística de la Edición Española de Libros con ISBN. CULTURABase. [En línea]. Disponible en http://www.culturaydeporte.gob.es/servicios-al-ciudadano/estadisticas/cultura/mc/culturabase/libro/resultados-libro.html

Informe Anual "La Sociedad en Red" 2011. (Edición 2012). Observatorio Nacional de las Telecomunicaciones y la Sociedad de la Información. Ministerio de Economía y Empresa. [En línea]. Disponible en https://www.ontsi.red.es/ ontsi/es/estudios-informes/informeanual-2011-edicion-2012

Informe Anual "La Sociedad en Red" 2017. (Edición 2018). Observatorio Nacional de las Telecomunicaciones y la Sociedad de la Información. Ministerio de Economía y Empresa. [En línea]. Disponible en https:// www.ontsi.red.es/ontsi/es/content/ informe-anual-la-sociedad-en-red2017-edici\%C3\%B3n-2018 